\title{
The national database of the German Collaborative Arthritis Centres: II. Treatment of patients with rheumatoid arthritis
}

\author{
A Zink, J Listing, $M$ Niewerth, $\mathrm{H}$ Zeidler, for the German Collaborative Arthritis Centres ${ }^{\star}$
}

\begin{abstract}
Objective-To describe current treatment of patients with rheumatoid arthritis (RA) in German rheumatology.

Methods-Data from the German rheumatological database of 1998, comprising clinical and patient questionnaire data of 12992 outpatients with RA seen at 24 collaborative arthritis centres in Germany, were analysed.
\end{abstract}

Results-At the time of documentation, $88 \%$ of the patients with RA were undergoing disease modifying antirheumatic drug (DMARD) treatment. Methotrexate (MTX) was prescribed to $56 \%$ of the patients $(61 \%$ with seropositive and $45 \%$ with seronegative RA). Combination treatment was used in $15 \%$. MTX was the drug of first choice even in patients with up to one year's disease duration $(49 \%)$, followed by antimalarial drugs (21\%). Patients treated by non-rheumatologists within the previous year had received DMARD treatment in only $33 \%$ of the cases. In steroid treatment, low doses ( $\leqslant 7.5 \mathrm{mg} / \mathrm{day}$ ) were used by rheumatologists much more often $(44 \%)$ than higher doses $(12 \%) .16 \%$ of the patients had been inpatients during the previous year, with a median length of stay accumulated over the year of 21 days. Together with stays in inpatient rehabilitation, $22 \%$ of all patients had had some form of inpatient treatment. Comprehensive measures such as occupational therapy and patient education were prescribed to fewer than $12 \%$ of the patients, mostly during their hospital stay.

Conclusion-German rheumatologists do follow recent recommendations about early and effective treatment. However, there are still deficits in outpatient care with non-medicinal measures like occupational therapy and patient education, which may partly explain the high hospital admission rates.

(Ann Rheum Dis 2001;60:207-213)

Drug treatment in rheumatoid arthritis (RA) has changed significantly within the past two decades. Until the end of the 1980 s most rheumatologists followed the pyramid approach, ${ }^{1}$ according to which a patient was first treated with a well tolerated drug of minor efficacy while more effective and more toxic drugs were given rather late in the course of the disease. Treatment usually started with non-steroidal anti-inflammatory drugs (NSAIDs) alone. Increasing evidence of the extent of joint erosion in early disease and the growing number of safe and effective disease modifying antirheumatic drugs (DMARDs) led to a revision of the dominant philosophy: the "remodelling of the pyramid". ${ }^{2}$ New treatment approaches, such as the "sawtooth strategy", became established, ${ }^{3}$ methotrexate (MTX) gained increasing importance, ${ }^{4}$ and the efficacy and safety of combination treatments was shown. ${ }^{56}$ Most rheumatologists today provide early aggressive treatment, ${ }^{7}$ with MTX as "anchor drug" in combination treatment. ${ }^{8}$ Corticosteroids were rediscovered for long term treatment, with low doses being preferred to prevent the feared complications of high doses, though this topic has been debated continuously in recent years. ${ }^{9-11}$

Little is known about the introduction of these new treatment strategies into daily rheumatological care outside of clinical studies. How intensively do rheumatologists respond to new recommendations and to what extent are they ready to change treatments with which they have had a long personal experienceespecially if there is still conflicting evidence as to the efficacy of a given treatment? Even less is known on the community level: How quickly, for example, do non-specialist doctors adopt treatment recommendations which have become established in the rheumatological community?

There are also few data about the role of comprehensive therapeutic measures. The guidelines of the American College of Rheumatology ${ }^{12}$ emphasise the essential role of comprehensive care. Initial treatment should include patient education, physical and occupational therapy as well as NSAIDs and, possibly, steroids. According to these guidelines, it is only in persisting, active disease that DMARD treatment should be introduced, together with the consultation of a rheumatologist. The guidelines also recommend that patient education be offered early in the disease. If we take these recommendations seriously, every patient with inflammatory polyarthritis should at least have the opportunity to participate in a programme of patient education. This seems to be far from becoming a reality, not only on the community level but also in rheumatological care itself.

Data from the German national rheumatological database were used to describe treatment patterns in patients with RA seen at the participating arthritis centres. 
Table 1 Disease modifying antirheumatic drug (DMARD) treatment within the previous 12 months in patients with rheumatoid arthritis by disease duration; comparison of new patients and patients treated by rheumatologists (1998; values are percentages)

\begin{tabular}{|c|c|c|c|c|}
\hline & \multicolumn{2}{|l|}{ All patients with $R A$} & \multicolumn{2}{|c|}{ Disease duration $<2$ years } \\
\hline & $\begin{array}{l}\text { Newly referred patients } \\
(\%)(n=1206)+\end{array}$ & $\begin{array}{l}\text { Patients treated by } \\
\text { rheumatologists }(\%) \\
(n=8716)\end{array}$ & $\begin{array}{l}\text { Newly referred patients } \\
(\%)(n=543) \neq\end{array}$ & $\begin{array}{l}\text { Patients treated by } \\
\text { rheumatologists (\%) } \\
(n=1016)\end{array}$ \\
\hline Antimalarial drugs & $3.2^{\star}$ & 15.0 & $0.6^{\star}$ & 17.1 \\
\hline SSZף & $9.0^{\star}$ & 14.5 & $5.2^{\star}$ & 18.3 \\
\hline Parenteral gold & $4.1^{\star}$ & 9.1 & $1.4^{\star}$ & 7.6 \\
\hline MTX & $15.7^{\star}$ & 53.5 & $8.2^{\star}$ & 44.1 \\
\hline AZA & $2.2^{\star}$ & 4.7 & 0.6 & 2.2 \\
\hline Other DMARDs & $2.8^{\star}$ & 7.5 & 1.4 & 4.5 \\
\hline Any of these drugs & $32.6^{\star}$ & 87.3 & $16.3^{\star}$ & 82.8 \\
\hline
\end{tabular}

The sums total more than $100 \%$ because some patients in both groups had received different individual drugs successively. ${ }^{\star}$ Differences are significant on the 0.001 level.

tWithout 189 cases who were referred by rheumatologists.

$\neq$ Without 35 cases who were referred by rheumatologists.

|SSZ = sulfasalazine; MTX = methotrexate; AZA = azathioprine.

\section{Patients and methods}

The structure and content of the database are described elsewhere in more detail. ${ }^{13}$ For the description of drug and complementary treatments, data from 1998 were used. Recent developments in the frequency of inpatient care were analysed using data from the years 1993-98. The number of outpatients with RA recorded in the database was 10383 in 1993, between 11391 and 12750 in each of the years 1994-97, and 12992 in 1998. As the decrease in hospital days and length of stay from 1993 to 1998 was linear, we report only the data for the years 1993 and 1998.

Diagnosis, disease duration, drug treatment as well as activity and severity of the disease, joint counts, and laboratory parameters in this database are registered by the doctor. "Severity" is measured by a five item Likert scale ("asymptomatic", "mild", "moderate", "severe", and "very severe"). Assessment of severity is made by considering the previous course of disease and the expected prognosis of a patient in comparison with other patients with the same disease. It reflects a more constant judgment over time compared with disease activity. In the analyses we grouped the first two items to "mild" and the last two to "severe". Non-drug treatments (physical therapy, patient education, stays in hospitals or rehabilitative clinics) are recorded by the patient.

Even though only rheumatologists and their patients contribute to the database, conclusions about the therapeutic behaviour of non-specialist doctors can be drawn: if we focus on new cases which were not treated by rheumatologists within the previous 12 months, treatment within this time frame can be attributed to the family doctor. On the other hand, by restricting our attention to patients who have been receiving continuous rheumatological care for at least the previous six months, we can describe the therapeutic behaviour of rheumatologists.

Drug treatments are recorded in two formats: as current treatments (day of registration) and treatments within the past 12 months. The first item is used to analyse present treatments including combination treatments in rheumatological care, whereas the second item is used to compare treatment behaviour in non-specialised care (newly referred patients) and in rheumatological care.

"Osteoporosis medication" comprises all treatments given with the aim of preventing and treating osteoporosis-that is, calcium, vitamin $\mathrm{D}$, hormones, bisphosphonates, fluorides. The database in 1998 did not differentiate between single drugs.

To compare treatments among rheumatologists on different levels of health care, case mix adjusted odds ratios and their 95\% confidence intervals (CI) were calculated. Case mix adjustment was performed by logistical regression analysis with respect to age, sex, disease duration, rheumatoid factor, disease severity, and disability score.

The program SPSS (Statistical Package for the Social Sciences ${ }^{14}$ ) was used for data entry and analysis.

\section{Results}

DRUG TREATMENTS WITHIN THE PREVIOUS 12 MONTHS

DMARD treatment

If we compare treatments during the previous 12 months in newly referred and continuously treated patients, the spectrum differs greatly between patients treated by doctors with and without a rheumatological subspecialisation (table 1). In 1998, 87\% of the patients with RA treated by rheumatologists had received any DMARD within the previous 12 months. Fifty four per cent were treated with MTX. Antimalarial drugs and sulfasalazine (SSZ) had been used with about the same frequency, followed by parenteral gold. All the other drugs were scarcely prescribed. In contrast, before the consultation of a rheumatologist, only 33\% of all patients with $\mathrm{RA}$ had received any DMARD; $16 \%$ had been prescribed MTX.

As newly referred patients have a shorter disease duration than patients receiving rheumatological treatment, in table 1 the two groups are compared also for patients with a disease duration of up to two years. Sixteen per cent of the new cases but $83 \%$ of the patients with fewer than two years' disease duration treated by rheumatologists had received DMARD treatment within the previous 12 months. MTX was the drug of first choice among rheumatologists and also in patients with less than two years' disease duration. 
Table 2 Other drug treatment within the previous 12 months in patients with rheumatoid arthritis; comparison of newly referred patients and patients treated by rheumatologists (1998; values are percentages)

\begin{tabular}{|c|c|c|c|c|}
\hline & \multicolumn{2}{|l|}{ All patients with $R A$} & \multicolumn{2}{|c|}{ Disease duration $<2$ years } \\
\hline & $\begin{array}{l}\text { Newly referred patients } \\
(\%)(n=1200) t\end{array}$ & $\begin{array}{l}\text { Patients treated by } \\
\text { rheumatologists (\%) } \\
(n=8583)\end{array}$ & $\begin{array}{l}\text { Newly referred patients } \\
(\%)(n=501) \neq\end{array}$ & $\begin{array}{l}\text { Patients treated by } \\
\text { rheumatologists (\%) } \\
(n=1206)\end{array}$ \\
\hline Analgetics & 4.5 & 6.8 & 3.6 & 6.0 \\
\hline NSAIDs $\uparrow$ & $51.7^{\star}$ & 61.6 & $42.3^{\star}$ & 57.3 \\
\hline Steroids ( $\leqslant 7.5 \mathrm{mg} /$ day) & $16.8^{\star}$ & 45.4 & $10.4^{\star}$ & 40.2 \\
\hline Steroids (>7.5 mg/day) & $18.7^{\star}$ & 12.0 & 14.4 & 18.6 \\
\hline Intra-articular steroids & $1.9^{\star}$ & 10.9 & $1.2^{\star}$ & 7.9 \\
\hline Osteoporosis treatment & $5.2^{\star}$ & 26.0 & $2.0^{\star}$ & 20.6 \\
\hline Antibiotics & 0.4 & 0.4 & 0.4 & 0.2 \\
\hline Any of these drugs & $72.2^{\star}$ & 92.4 & $60.3^{\star}$ & 90.6 \\
\hline
\end{tabular}

*Differences are significant on the 0.001 level.

tWithout 189 cases who were referred by rheumatologists.

¥Without 35 cases who were referred by rheumatologists.

INSAIDs = non-steroidal anti-inflammatory drugs.

The difference between rheumatological and non-specialised care is not restricted to early arthritis: $52 \%$ of newly referred cases with a disease duration of more than two years had not received a DMARD within the previous 12 months compared with $12 \%$ of those who had been in rheumatological care.

\section{Non-DMARD drug treatments}

There were also differences between nonspecialist doctors and rheumatologists in the use of other drugs (table 2): $17 \%$ of the patients treated by non-rheumatologists within the previous 12 months but $45 \%$ of those treated by rheumatologists had received low dose corticosteroids ( $\leqslant 7.5 \mathrm{mg} /$ day) in this period. The frequency of use of "high dose" corticosteroids (>7.5 mg/day) was slightly higher in newly referred patients. Rheumatologists used injectable corticosteroids more often. There was also a marked difference in the prescription of drugs to treat osteoporosis: because RA and steroid treatment constitute risk factors for osteoporosis, about one quarter of all patients with RA treated by rheumatologists received some drug treatment for this condition as compared with only $5 \%$ of the patients treated by non-specialists. Rheumatologists more often used NSAIDs than non-rheumatologists.

To control for the differential influence of disease duration in the two groups, we again compared patients with fewer than two years of disease. Although there is only a small difference in the frequency of prescriptions of high dose corticosteroids between nonspecialist doctors and rheumatologists in this group, the difference for low dose steroids was more marked: $10 \%$ of all patients treated by non-rheumatologists and $40 \%$ of those undergoing treatment by rheumatologists had received low dose steroid treatment. Comparisons within the group of patients with a short disease duration show that the differences between the two groups of doctors cannot be attributed to differences in disease duration. The same holds true if we control for disease activity or severity (data not shown).
CURRENT DRUG TREATMENT IN RHEUMATOLOGICAL CARE

\section{DMARD treatment}

At the time of documentation $90 \%$ of the seropositive and $84 \%$ of the seronegative patients with RA were undergoing DMARD treatment (table 3). MTX was prescribed to $61 \%$ of the seropositive and $45 \%$ of the seronegative patients, mostly as a single treatments. In 17\% of the seropositive and almost $10 \%$ of the seronegative patients combination treatments were given. The most common combinations were MTX and antimalarial drugs, and methotrexate with SSZ. Triple treatment (MTX, SSZ, and antimalarial drugs) was used in less than $1 \%$ of the patients.

If we consider only patients with a disease duration of up to two years who had been undergoing treatment by a rheumatologist for at least the previous six months, $91 \%$ were receiving DMARD treatment. In this group MTX (alone or in combination) was given to $51 \%$ of the patients. Antimalarial drugs ranked second with $21 \%$, followed by SSZ with $18 \%$. Of all DMARD treatments in this group of patients, $11 \%$ were combination treatments. For patients with fewer than 12 months' disease duration and a very early start for their rheumatological treatment (within six months of symptom onset) the figures are similar: $91 \%$ were receiving DMARD treatment, $49 \%$ of these patients received MTX, antimalarial drugs were prescribed for $21 \%$, SSZ for $19 \%$. Combination treatment was given in $9 \%$ of these early cases.

As was to be expected, in general, MTX was used more frequently in cases the doctors rated as more severe (table 4 ): $39 \%$ of mild but $62 \%$ of moderate and $68 \%$ of patients with severe RA received MTX treatment, either alone or in combination. MTX was given in combination with another DMARD in $28 \%$ of severe cases. On the other hand, SSZ and antimalarial drugs were preferentially used in mild cases.

There were differences in the use of single DMARDs between the rheumatology units at different levels of care. Rheumatologists in individual practices used MTX almost as frequently as those in academic or other hospitals $(54 \%$ in practices compared with $55 \%$ in academic and $59 \%$ in non-university hospitals). In patients with mild RA, however, MTX 
Table 3 Current disease modifying antirheumatic drug (DMARD) treatment in outpatients with $R A$ in rheumatological care with respect to rheumatoid factor (1998; values are percentages)

\begin{tabular}{lccc}
\hline & $\begin{array}{l}\text { Seropositive } R A \\
(n=5948)\end{array}$ & $\begin{array}{l}\text { Seronegative } R A \\
(n=2999)\end{array}$ & $\begin{array}{l}\text { Total } \\
(n=8947)\end{array}$ \\
\hline Single treatments & $6.6^{\star}$ & 15.6 & 8.9 \\
Antimalarial drugs & $7.6^{\star}$ & 11.7 & 9.0 \\
SSZ† & 5.1 & 6.1 & 5.4 \\
Parenteral gold & $45.7^{\star}$ & 36.6 & 42.7 \\
MTX† & 3.3 & 2.5 & 3.1 \\
AZA† & 4.7 & 4.4 & 4.6 \\
Other DMARDs & $5.6^{\star}$ & 3.0 & 4.7 \\
Combination treatments & $3.6^{\star}$ & 1.9 & 3.0 \\
MTX with antimalarial drugs & $5.8^{\star}$ & 3.2 & 4.9 \\
MTX with SSZ & 2.2 & 1.4 & 1.9 \\
Other combination with MTX & $17.1^{\star}$ & 9.5 & 14.6 \\
Other combination without MTX & & & 15.5 \\
Total of combinations & $14.3^{\star}$ & 17.7 & 13.3 \\
Total & 12.7 & 14.5 & 85.5 \\
Antimalarial drugs & $60.8^{\star}$ & 44.9 & 8.3 \\
SSZ & $90.3^{\star}$ & 84.4 & \\
MTX & & & \\
Any DMARD & & & \\
\hline
\end{tabular}

$\star$ Differences are significant on the 0.001 level.

$+\mathrm{SSZ}=$ sulfasalazine; $\mathrm{MTX}=$ methotrexate; $\mathrm{AZA}=$ azathioprine .

Table 4 Current disease modifying antirheumatic drug (DMARD) treatment in outpatients with $R A$ in rheumatological care with respect to disease severity (1998; values are percentages)

\begin{tabular}{|c|c|c|c|}
\hline & Mild $(n=2861)$ & $\begin{array}{l}\text { Moderate } \\
(n=4164)\end{array}$ & $\begin{array}{l}\text { Severe } \\
(n=1672)\end{array}$ \\
\hline \multicolumn{4}{|l|}{ Single treatments } \\
\hline Antimalarial drugs* & $15.6^{\star}$ & 7.4 & $1.7^{\star}$ \\
\hline $\mathrm{SSZ}^{\star}+$ & $12.1^{\star}$ & 9.1 & $3.5^{\star}$ \\
\hline Parenteral gold $\star$ & $8.4^{\star}$ & 4.2 & 3.3 \\
\hline $\mathrm{MTX}^{\star}+$ & $33.2^{\star}$ & 48.8 & $42.7^{\star}$ \\
\hline $\mathrm{AZA}^{\star}+$ & $1.7^{\star}$ & 3.1 & $5.1^{\star}$ \\
\hline Other DMARDs & $5.1^{\star}$ & 3.9 & 5.7 \\
\hline \multicolumn{4}{|l|}{ Combination treatments } \\
\hline MTX with Antimalarial drugs $\star$ & $2.1^{\star}$ & 5.0 & $8.7^{\star}$ \\
\hline MTX with SSZ^ & $1.2^{\star}$ & 3.6 & 5.1 \\
\hline Other combinations with $\mathrm{MTX}^{\star}$ & $2.3^{\star}$ & 4.4 & $10.9^{\star}$ \\
\hline Combinations without $\mathrm{MTX}^{\star}$ & $0.9^{\star}$ & 2.0 & 3.3 \\
\hline Total of combinations ${ }^{\star}$ & $6.4^{\star}$ & 15.1 & $28.1^{\star}$ \\
\hline \multicolumn{4}{|l|}{ Total } \\
\hline Antimalarial drugs* & $18.5^{\star}$ & 14.4 & 13.7 \\
\hline SSZ & 13.9 & 14.1 & 10.9 \\
\hline $\mathrm{MTX}^{\star}$ & $38.7^{\star}$ & 62.0 & $67.9^{\star}$ \\
\hline Any DMARD* & $82.5^{\star}$ & 91.7 & 90.3 \\
\hline
\end{tabular}

*Differences from "moderate" are significant at the 0.001 level.

$+\mathrm{SSZ}=$ sulfasalazine; $\mathrm{MTX}=$ methotrexate; $\mathrm{AZA}=$ azathioprine .

Table 5 Current non-disease modifying antirheumatic drug (DMARD) treatment in outpatients with $R A$ in rheumatological care with respect to disease severity (1998; values are percentages)

\begin{tabular}{lcclc}
\hline & $\begin{array}{c}\text { Mild } \\
(n=2797)\end{array}$ & $\begin{array}{l}\text { Moderate } \\
(n=4059)\end{array}$ & $\begin{array}{l}\text { Severe } \\
(n=1637)\end{array}$ & $\begin{array}{l}\text { Total } \\
(n=8493)\end{array}$ \\
\hline Analgetics & 4.6 & 6.6 & $11.7^{\star}$ & 6.9 \\
NSAIDs $\dagger$ & $51.8^{\star}$ & 61.4 & $67.0^{\star}$ & 59.3 \\
Steroids ( $\leqslant 7.5 \mathrm{mg}$ /day) & $31.3^{\star}$ & 51.0 & $56.8^{\star}$ & 45.6 \\
Steroids (>7.5 mg/day) & $3.8^{\star}$ & 9.7 & $21.2^{\star}$ & 10.0 \\
Intra-articular steroids & $2.2^{\star}$ & 7.7 & $12.2^{\star}$ & 6.8 \\
Drugs against osteoporosis & $15.6^{\star}$ & 29.9 & $46.7^{\star}$ & 28.4 \\
Any of these treatments & $81.0^{\star}$ & 95.6 & $98.0^{\star}$ & 91.3 \\
\hline
\end{tabular}

*Differences from "moderate" are significant at the 0.001 level.

†NSAIDs - non-steroidal anti-inflammatory drugs.

was used in $27 \%$ of cases in individual practices compared with $43 \%$ both at outpatient clinics of universities and rheumatology hospitals. In severe cases there was again no difference between the two types of hospital, but more prescription of MTX in individual rheumatology practices $(65 \%$ and $64 \%$ in outpatient clinics and $76 \%$ in individual practices). Antimalarial drugs were preferentially used by rheumatologists in practices: they prescribed these drugs to $26 \%$ of their patients with RA compared with $9 \%$ at academic and $11 \%$ at other hospitals $36 \%$ of mild cases compared with $11 \%$ at academic and $9 \%$ at other hospital outpatient clinics).

To test whether these differences were significant, we calculated case mix adjusted odds ratios for the prescription of single drugs (see "Patients and methods" section). As the two types of hospital outpatient clinics provided similar treatment, we added their figures up and compared only outpatient clinics with individual rheumatology practices.

Compared with patients treated at outpatient clinics, patients with RA in individual practices had a threefold chance of being treated with antimalarial drugs $(\mathrm{OR}=3.04$; CI 2.65 to 3.49). SSZ had an OR of 1.39 (CI 1.20 to 1.60), whereas the likelihood of treatment with MTX (OR=0.65, CI 0.58 to 0.73 ) and with other DMARDs like azathioprine $(\mathrm{OR}=0.49$; CI 0.43 to 0.56$)$ was significantly lower. Combination treatments were given with equal frequency $(\mathrm{OR}=1.02$; CI 0.89 to 1.17).

These differences cannot be explained by differential ratings of severity depending on the institutional setting: when we did the same calculations with patient derived data (disability), we obtained very similar results (data not shown).

\section{Non-DMARD treatment}

On the day of registration, NSAIDs were used in $52 \%$ of the patients with mild, $61 \%$ of those with moderate, and $67 \%$ of the patients with severe disease (table 5). High dose steroids were almost exclusively used in patients with a higher disease severity. The frequency of osteoporosis drugs use was strongly associated with the perceived severity of the disease.

\section{Combinations of DMARDs with other drugs}

Usually, patients received DMARDs combined with NSAIDs and/or oral corticosteroids: $22 \%$ of all patients with RA received steroids and DMARDs alone, $24 \%$ NSAIDs and DMARDs, and $29 \%$ took a combination of all three forms of treatment. Only $13 \%$ of all patients were treated with DMARDs alone. Methotrexate was more often combined with low dose corticosteroids than other DMARDs: although the proportion of patients treated with high dose steroids was about $10 \%$ irrespective of the DMARD used, $54 \%$ of the patients undergoing MTX treatment but only $34 \%$ receiving treatment with SSZ and 28\% receiving antimalarial drugs were also taking low dose steroids. NSAIDs were used with equal frequency in combination with the different DMARDs. Of the patients with a very short disease duration ( $<1$ year), $41 \%$ received MTX and steroids.

NON-DRUG TREATMENTS DURING THE PREVIOUS 12 MONTHS

The patients recorded all non-medicinal treatments they had received within the previous 12 months as either inpatients or outpatients (table 6). Forty four per cent of all patients with RA had received individual therapeutic exercises. Another $17 \%$ had participated in group physiotherapy. Passive measures were pre- 
Table 6 Non-drug treatments received by patients with $R A$ in inpatient or outpatient care within the previous 12 months; only patients treated by rheumatologists within the previous six months are included (1998; values are percentages)

\begin{tabular}{llll}
\hline & $\begin{array}{l}\text { Patients with in- or } \\
\text { outpatient treatment } \\
(n=8001)\end{array}$ & $\begin{array}{l}\text { Patients with } \\
\text { inpatient treatment } \\
(n=1635)\end{array}$ & $\begin{array}{l}\text { Patients with } \\
\text { outpatient treatment } \\
\text { only }(n=5465)\end{array}$ \\
\hline Individual physiotherapy & 44.3 & 61.3 & 36.3 \\
Group physiotherapy & 17.3 & 50.2 & 6.7 \\
Massages & 29.4 & 48.6 & 21.8 \\
Electrotherapy & 18.1 & 31.2 & 13.0 \\
Occupational therapy & 14.8 & 48.9 & 4.6 \\
Patient education & 5.7 & 20.0 & 1.5 \\
Any of these treatments & 66.8 & 86.9 & 59.7 \\
\hline
\end{tabular}

scribed less frequently but still $29 \%$ of the patients had received massages and $18 \%$ some form of electrotherapy.

Compared with these treatments, there was a low prescription rate of comprehensive measures such as occupational therapy (including joint protection) and patient education. Only $15 \%$ of the patients with RA had received any occupational therapy and only $6 \%$ any patient education.

If we consider only patients receiving inpatient treatment during the previous year, $61 \%$ of them had had physiotherapy during their hospital stay. Group physiotherapy, massages, and occupational therapy were given to about half of the patients, one third received electrotherapy, and $20 \%$ patient education. Thus more than half of all comprehensive treatments were given during inpatient care. As outpatients, only $5 \%$ had received occupational therapy and $2 \%$ patient education.

INPATIENT CARE IN HOSPITALS AND REHABILITATION UNITS DURING THE PREVIOUS 12 MONTHS

Germany has a traditional system of specialised rehabilitation hospitals at spas, where a considerable part of rheumatological inpatient care is performed. These hospitals aim at reducing disability and handicap resulting from chronic diseases and strengthening self help abilities. Under current German health law, patients are entitled to go to these spas for treatment every three to four years for about three weeks. Rehabilitation hospitals are usually located outside the residential areas where the patients live. In contrast, acute problems such as flares are dealt with at (rheumatology) hospitals located in the patients' residential areas. To estimate the amount of inpatient treatment that is provided to these patients, both stays in hospitals for acute conditions and stays in rehabilitation hospitals have to be considered.

Stays in hospitals

In the past, German patients with RA were treated in inpatient care much more often than today. This can be shown by comparing the data for the years 1993-98. The proportion of patients with RA with stays in hospitals during some part of the previous year decreased continuously from $28 \%$ in 1993 (start of the database) to $16 \%$ in 1998 (for seropositive RA from $29 \%$ to $18 \%$ and for seronegative RA from $26 \%$ to $13 \%$ ).

At the same time, the length of stay also went down: the cumulative mean length of stay during the previous 12 months for those patients with RA who had had any inpatient treatment decreased from 29 days in 1993 (median 25 days) to 24 days in 1998 (median 21 days). The proportion of patients with a total of fewer than three weeks' stay in hospital a year among all patients who had received inpatient treatment rose from $43 \%$ in 1993 to $65 \%$ in 1998 .

If we calculate the annual hospital days for each patient with RA recorded in the database, the reduction in frequency and duration becomes even more apparent: the mean number of hospital days for each patient decreased continuously from 8.1 in 1993 to 3.8 in 1998.

\section{Stays in rehabilitation clinics}

In addition to the inpatient treatments described above, $30 \%$ of all patients had ever been to a rehabilitation hospital, $11 \%$ during the previous year. Compared with the previous years, with a constant level of about $14 \%$, this was a significant decrease.

In total, $22 \%$ of all patients with RA in 1998 had received some form of inpatient treatment during the previous year compared with $37 \%$ in 1993.

\section{Discussion}

In $1998,84 \%$ of patients with RA with a disease duration of up to two years who had been newly referred to German rheumatologists had not had any DMARD treatment within the previous 12 months. If it is taken into account that the initiation of DMARD treatment is a major reason for the consultation of a rheumatologist, this figure may be acceptable for patients with very early disease. However, $48 \%$ of the new referrals with more than two years' disease duration had not received any DMARD treatment within the previous 12 months either. The perceived severity of the disease (doctor's rating) of these patients did not differ from that of patients whose rheumatological treatment had started earlier and who had an equal disease duration. We therefore cannot assume that the patients with a later onset of rheumatological care had milder diseases and were admitted only because of acute deterioration, even though we do not have any data about the patients' clinical status before admission. These data correspond to findings from a population based RA panel in California (1984-93), where the probability of starting MTX treatment was 10 times higher in patients who had had at least some contact with a rheumatologist than in those who had only been receiving treatment by nonrheumatologists. ${ }^{15}$ Also, a German population study in 1989 found a DMARD prescription rate of $22 \%$ only in patients treated by non-rheumatologists. ${ }^{16}$

During the past decade, MTX has become the drug of first choice in the treatment of RA in rheumatology. ${ }^{45}{ }^{17-19}$ This is reflected in current practice in German rheumatology, even in patients with short disease duration. Half of all patients with up to two years' disease duration were currently treated with MTX. For patients with very short disease duration $(<1$ year, mean seven months) our data can be 
compared with findings from a recent American inception cohort study with 750 patients with a mean disease duration of five months enrolled by 142 rheumatologists. ${ }^{20}$ Sixty four per cent received at least one DMARD $(91 \%$ in our data), $25 \%$ took MTX (49\% in our data), and $29 \%$ antimalarial drugs $(21 \%$ in our data). SSZ was only prescribed to $5 \%$ of the patients in the USA, which is clearly different from our data with $19 \%$. The frequency of combination treatment was higher in the American cohort $(15 \%)$ than in our data $(9 \%)$.

We found differences between the treatment behaviour of rheumatologists in individual practice and that of rheumatologists working in hospitals, with more antimalarial drugs and a strong dependence on the use of MTX from the perceived severity of the disease in individual practices. After case mix adjustment the probability of using MTX in practices was one third lower than in hospitals. There was, however, no difference in the use of MTX in severe cases and the frequency of combination treatment. This corresponds with findings from a population based pharmacoeconomic programme in the USA and Canada, with $44 \%$ using MTX alone in academic and $28 \%$ in community sites but no difference in the use of combination treatment. Rheumatologists in individual practices seem to be more cautious with cases they rate as less severe but use all existing possibilities in severe cases.

In a survey of 4032 American and 950 European (British and Dutch) rheumatologists dealing with preferences for the prescription of single, double, and triple DMARD treatments, ${ }^{21}$ European rheumatologists were more satisfied with SSZ than American rheumatologists. When double treatments were considered necessary, most American rheumatologists would use MTX with hydroxychloroquine, whereas the majority of European rheumatologists would use MTX with SSZ. In our data, combinations of MTX with antimalarial drugs were slightly more common than with SSZ. The readiness to use combination treatments in cases of severe RA in the survey was higher in the USA (58\%) than in Europe $(32 \%)$. In our data, combination treatments were given in $28 \%$ of all cases of severe RA, which is in accordance with other European countries. Triple treatment (MTX, SSZ, and antimalarial drugs), which has been shown to be safe and effective, ${ }^{22}$ was rarely used $(<1 \%)$ by German rheumatologists in 1998.

The differences between European and American rheumatologists are underlined by a recent survey, ${ }^{23}$ in which 200 American rheumatologists were asked about their treatment behaviour. In 1999, 46\% of all rheumatologists stated that they used combination treatment in more than $30 \%$ of their patients with RA; $96 \%$ stated that they used any combination treatment. American rheumatologists seem to differ from their German colleagues in the use of DMARD combination treatment.

The frequency of prescription of prednisone was $54 \%$ of all patients with RA in the Californian longitudinal RA panel. ${ }^{24}$ This finding is in agreement with our data of low dose cortico- steroid prescription in $46 \%$ and high dose prescription in $10 \%$ of the patients treated by rheumatologists. In the American inception cohort $^{20} 55 \%$ of the patients with less than one year of disease received DMARDs with prednisone compared with $41 \%$ in our data.

Compared with data from a Canadian study on the use of health services, ${ }^{25}$ where the mean number of visits for all patients with RA to physical and occupational therapy was $1.5 \mathrm{a}$ year, the prescription of non-drug treatments like physiotherapy and massage in Germany is relatively high. Each prescription includes six or 10 visits to a therapist, many patients receiving several prescriptions a year. Even though we do not know the total number of visits, our data indicate a higher therapeutic intensity in this field in Germany.

However, given that it is recommended, ${ }^{10}$ and German rheumatologists share this opinion, that patient education should be one of the first steps in the treatment of RA, there is a huge gap between theory and practice. Only $6 \%$ of all patients with RA had participated in a patient education programme within the previous 12 months, most of them while inpatients in a hospital or rehabilitation clinic. In the Edmonton cohort $38 \%$ of the patients had attended a patient education programme at some time during their disease (mean disease duration 6.5 years), about half of these within the first two or three years of disease onset. ${ }^{26}$ Occupational therapy is another area of clear deficiency: only $5 \%$ of the patients had received occupational therapy (including joint protection advice) within the previous year as outpatients, $15 \%$ if inpatient care is included. Inpatient treatments, at least in part, compensate for the deficits in outpatient complementary treatments.

Traditionally, inpatient treatment used to be common in Germany compared with other countries. In German rheumatology in 1993, $28 \%$ of all patients with RA had been treated in hospitals within the previous 12 months compared with $23 \%$ in Canada (Saskatoon and Montreal) between 1990 and 1994. ${ }^{25}$ There has been a considerable decrease in admission of patients with RA to hospital in Germany ( $16 \%$ in 1998). This corresponds with much earlier data of 1981 from four rheumatology centres in the USA, where $15 \%$ of all patients with RA had been in inpatient care with a mean length of stay for each patient of 14 days a year. ${ }^{27}$ Even though the frequency of inpatient treatments was comparable with this earlier data, the length of stay in Germany in 1998 was still rather high (mean 24 days during a 12 month period for patients who had been in hospital).

In addition to inpatient treatment in regular hospitals, Germany has an extended system of rehabilitation clinics at spas. Of all patients with RA, 30\% had at some point been to a rehabilitation clinic, $11 \%$ within the previous 12 months. Twenty two per cent had received one of these forms of inpatient treatment during the previous 12 months. The justification for this becomes clear when one considers that short term admission to a hospital rheumatol- 
ogy unit has been proved to reduce disease activity substantially, patients benefiting from it for at least two years. ${ }^{29}{ }^{30}$ Additionally, the deficits in occupational therapy and patient education in outpatient care in Germany are compensated for by inpatient treatments. None the less, the question should be asked whether this is cost effective.

The authors are especially grateful to Drs E Gromnica-Ihle (Berlin), R Rau (Ratingen), and U von Hinüber (Hildesheim) who enrolled more than 1000 patients each.

Supported by a grant from the German Federal Ministry of Health (FB2-433346-8/13).

Appendix: Participating German collaborative arthritis centres (speakers)

Aachen/Köln/Bonn (E Genth), Berlin (J Sieper), Dresden (HE Schröder), Düsseldorf (M Schneider), Erlangen (G Weseloh), Westliches Ruhrgebiet (H Warnatz), Gießen/Bad Nauheim (KL Schmidt), Greifswald (D Köster), Hannover (H Zeidler), Heidelberg (W Eich), Jena (G Hein), Leipzig (H Häntzschel), Lübeck/ Bad Bramstedt (WL Gross), Magdeburg/Vogelsang (J Kekow), Mainz/Bad Kreuznach (R Dreher), München (M Schattenkirchner), Münster (M Gaubitz), Ostwestfalen/Lippe (H Mielke), Regensburg/Bad Abbach (B Lang), Rhein-Main (JP Kaltwasser), Rostock (M Keysser), Saarland (M Pfreundschuh), Südbaden (HH Peter), Südwürttemberg (R Maleitzke)

1 Smythe CJ. Therapy of rheumatoid arthritis: a pyramidal plan. Postgrad Med 1972;51:31-9.

2 Wilske KR, Healey LA. Remodeling the pyramid: a concept whose time has come. J Rheumatol 1989;16:565-7.

3 Fries JF. Re-evaluating the therapeutic approach to rheumatoid arthritis: the 'sawtooth' strategy. J Rheumatol 1990 ; 17(suppl 25):12-15

4 Collins D, Bellamy N, Campbell J. A Canadian survey of current methotrexate prescribing practices in rheumatoid arthritis. J Rheumatol 1994;21:1220-3.

5 Jaffe IA. Combination therapy of rheumatoid arthritis: rationale and overview. J Rheumatol 1990;17(suppl 25): ration $24-7$.

6 Mottonen T, Hannonen P, Leirisalo-Repo M, Nissila M, Kautiainen $\mathrm{H}$, Korpela $\mathrm{M}$, et al. Comparison of combination therapy with single-drug therapy in early rheumatoid arthritis: a randomised trial. FIN-RACo trial group. Lancet 1999;353:1568-73

7 van der Heide A, Jacobs JW, Bijlsma JW, Heurkens AH, van Booma-Frankfort C, van der Veen MJ, et al. The effectiveness of early treatment with 'second line' antirheumatic drugs: a randomized, controlled trial. Ann Intern Med 1996;124:699-707

8 Pincus T, O'Dell JR, Kremer JM. Combination therapy with multiple disease-modifying antirheumatic drugs in rheumatoid arthritis: a preventive strategy. Ann Intern Med 1999;131:768-74.

9 Kirwan JR, Russel AS. Editorial review. Systemic glucocorticoid treatment in rheumatoid arthritis - a debate. Scand J Rheumatol 1998;27:247-51.

10 Boers $M$. The case of corticosteroids in the treatment of early rheumatoid arthritis [editorial]. Rheumatology 1999; 38:95-7.
11 Morrison E, Capell HA. Corticosteroids in rheumatoid arthritis - the case against [editorial]. Rheumatology 1999; arthritis - the

12 American College of Rheumatology ad hoc committee on clinical guidelines. Guidelines for the management of rheumatoid arthritis. Arthritis Rheum 1996;39:713-22.

13 Zink A, Listing J, Klindworth C, Zeidler $\mathrm{H}$ for the German Collaborative Arthritis Centres. The national database of the German Collaborative Arthritis Centres: I. Structure, aims, and patients. Ann Rheum Dis 2001;60:199-206.

14 Norusis MJ. SPSS advanced statistics 6.1. Chicago: SPSS Inc. 1994

15 Criswell LA, Such CL, Yelin EH. Differences in the use of second-line agents and prednisone for treatment of rheumatoid arthritis by rheumatologists and nonrheumatologists. J Rheumatol 1997;24:2283-90.

16 Wasmus A, Kindel P, Raspe HH. Epidemiologie der Behandlung bei an chronischer Polyarthritis Erkrankten in Hannover (Epidemiology of treatment of rheumatoid arthritis in Hanover). Z Rheumatol 1991;18:334-8.

17 Emery P. Rheumatoid arthritis: not yet curable with early intensive therapy (commentary). Lancet 1997;350:304-5.

18 Ward MM, Fries JF. Trends in antirheumatic medication use among patients with rheumatoid arthritis, 1981-1996. J Rheumatol 1998;25:408-16.

19 Conaghan PG, Crotty M, Oh E, Day RO, Brooks PM. Antirheumatic drug-prescribing behaviour of Australasian rheumatologists. Br J Rheumatol 1997;36:487-90.

20 Wolfe F, Pincus T, Fries JF, and the US Inception Cohort Group. Use of second line 'disease modifying' antirheumatic drugs (DMARDs) within 5 months of disease onset by $64 \%$ of 750 rheumatoid arthritis patients under care of 142 US rheumatologists: an inception cohort study [abstract]. Arthritis Rheum 1997;40(suppl 9):S218.

21 Moreland LW, Kimberly RP, Alarcon GS. European and US rheumatologists agree on triple but not on double or single early DMARD choice for different types of RA [abstract]. Arthritis Rheum 1997;40:(suppl 9):S218.

22 O'Dell JR, Haire CE, Erikson N, Drymalski W, Palmer W, Eckhoff PJ, et al. Treatment of rheumatoid arthritis with methotrexate alone, sulfasalazine and hydroxychloroquine, or a combination of all three medications. N Engl J Med 1996;334:1287-91.

23 Mikuls TR, O'Dell JR. The changing face of rheumatoid arthritis therapy: results of serial surveys. Arthritis Rheum 2000;43:464-7.

24 Criswell LA, Henke CJ. What explains the variation among rheumatologists in their use of prednisone and second line agents for the treatment of rheumatoid arthritis? J Rheumatol 1995;22:829-35.

25 Clarke AE, Zowall H, Levinton C, Assimakopoulos H, Sibley JT, Haga M, et al. Direct and indirect medical costs incurred by Canadian patients with rheumatoid arthritis: a 12 year study. J Rheumatol 1997;24:1051-60.

26 Suarez-Almazor ME, Soskolne CL, Saunders LD, Russell AS. Use of second line drugs for the treatment of rheumatoid arthritis in Edmonton, Alberta. Patterns of prescription and longterm effectiveness. J Rheumatol 1995;22: $836-43$

27 Wolfe F, Kleinheksel SM, Spitz PW, Lubeck DP, Fries JF, Young DY, et al. A multicenter study of hospitalization in rheumatoid arthritis. Frequency, medical-surgical admissions, and charges. Arthritis Rheum 1986;29:614-19.

28 Wolfe F, Kleinheksel SM, Spitz PW, Lubeck DP, Fries JF, Young DY, et al. A multicenter study of hospitalization in rheumatoid arthritis: effect of health care system, severity, and regional difference. J Rheumatol 1986;13:277-84.

29 Anderson RB, Needleman RD, Gatter RA, Andrews RP, Scarola JA. Patient outcome following inpatient vs outpatient treatment of rheumatoid arthritis. J Rheumatol 1988;15:556-60

30 Vliet Vlieland TP, Breedveld FC, Hazes JM. The two-year follow-up of a randomized comparison of in-patient multidisciplinary team care and routine out-patient care for active rheumatoid arthritis. Br J Rheumatol 1997;36:82-5. 